Published online 2017 April 13.

Abstract

\title{
Ultrasound Technique in Evaluation of Abdominal Wall Hernia
}

\author{
Hosein Rezaei, ${ }^{1,}{ }^{*}$ Bita Abbasi, ${ }^{1}$ and Farrokh Seilanian Tossie ${ }^{1}$ \\ ${ }^{1}$ Mashhad University of Medical Sciences, Mashhad, Iran \\ "Corresponding author: Hosein Rezaei. E-mail: rezaiH@mums.ic.ir
}

Received 2016 December 21; Accepted 2017 February 08.

\begin{abstract}
Background: Some sonographic positions for detection of abdominal wall hernias needed .In this paper we described the sonographic technique of abdominal wall hernia.

Methods: From June 2013 to July 2016, three hundred seventy four patients referred in our department for evaluation of abdominal wall hernia (median age, 38 years; range 2 - 86 years). One hundred and ninety patients had abdominal hernia, 85 in inguinal-femoral regions, 58 in epigastria and Para-umbilical, 34 incisional and 13 Spigelian. Men most referred for inguinal regions, the women frequently referred for femoral, Para-umbilical and inscional hernia. All the patients are examined by one instrument with linear and convex multi-frequencies probes. Sononography performed first in supine position with and without valsalva manor, sitting and if possible standing view then added. Patients who operated after sonography the surgery reports compared with our findings. Conclusions: Although sonography routine request for diagnosis of abdominal wall hernia, experience and various positions needed for correct diagnosis. In this paper we described our experience in sonography of abdominal wall hernia.
\end{abstract}

Keywords: Hernia, Sonography, Abdominal Wall

This is an abstract presented in the 33rd Iranian congress of radiology (ICR) and the 15th congress of Iranian radiographic science association (IRSA).

Copyright (c) 2017, Tehran University of Medical Sciences and Iranian Society of Radiology. This is an open-access article distributed under the terms of the Creative Commons Attribution-NonCommercial 4.0 International License (http://creativecommons.org/licenses/by-nc/4.0/) which permits copy and redistribute the material just in noncommercial usages, provided the original work is properly cited. 